Reprod. Nutr. Dévelop., 1988, 28 (1), 195-196.

\title{
Effets de la clonidine (alpha-2 agoniste) sur la lipolyse du tissu adipeux de bovin adulte, in vitro
}

Y. CHILLIARD, Jeanne FLECHET

Laboratoire de la Lactation,

I.N.R.A., Theix, 63122 Ceyrat, France.

Summary. In vitro lipolysis (glycerol release) by pieces of subcutaneous and/or perirenal bovine adipose tissue was measured after stimulation by isoproterenol (a beta-agonist) associated with adenosine deaminase. In 4 of the 5 animals that were studied, clonidine (an alpha-2 agonist) significantly inhibited glycerol release. The inhibitory effect of clonidine was greatest at the lowest concentrations (dose response $10^{-10}-10^{-4} \mathrm{M}$ ).

La lipolyse est une des voies métaboliques qui contrôlent le dépôt et la mobilisation des lipides corporels. Les catécholamines peuvent la stimuler par l'intermédiaire de récepteurs bêta-adrénergiques situés sur la membrane des adipocytes. Toutefois, ces mêmes hormones peuvent aussi l'inhiber, en stimulant des récepteurs de type alpha-2. II en résulte que l'effet des catécholamines est sous la dépendance du rapport entre les récepteurs bêta et alpha-2 des adipocytes.

La présence de récepteurs de type alpha-2 a été montrée chez l'homme loù elle est plus marquée dans les tissus adipeux sous-cutanés), le chien, le hamster et le lapin, mais pas chez le rat, la souris et le porc (revue de Lafontan, 1986). En l'absence de données publiées sur les bovins, l'objet du présent travail est de tester l'existence d'un éventuel effet de la clonidine (alpha-2 agoniste de synthèse) sur la lipolyse des tissus adipeux de bovins adultes, in vitro.

Matériel et méthodes. Du tissu adipeux périrénal et/ou sous-cutané de la croupe est prélevé sur bovins adultes (cf. tabl. 1) immédiatement après abattage, placé à $39^{\circ} \mathrm{C}$ et découpé en morceaux d'environ $30 \mathrm{mg}$. Environ $300 \mathrm{mg}$ de tissu sont incubés sous agitation dans $1,5 \mathrm{ml}$ de tampon Krebs-Ringer bicarbonaté à $\mathrm{pH} 7,4$ contenant $3 \%$ d'albumine et du glucose $(3 \mathrm{mM})$. Après $20 \mathrm{~min}$ de préincubation, on ajoute les différents effecteurs de la lipolyse et on prélève deux fois $0,15 \mathrm{ml}$ de milieu à $90 \mathrm{~min}$ d'intervalle pour déterminer la quantité de glycérol libéré, en utilisant une modification de la méthode enzymatique de Wieland (1957). Les effecteurs utilisés sont l'isoprénaline (Isuprel, Winthrop), I'adénosine désaminase (Boehringer Mannheim) et la clonidine (gracieusement fournie par Boehringer Ingelheim).

Résultats et discussion. La lipolyse est augmentée de 1,6 à 6 fois en présence d'isoprénaline (bêta-agoniste) et d'adénosine désaminase (tabl. 1). L'addition de clonidine $\left(10^{-8} \mathrm{M}\right.$ ) entraîne des inhibitions (de -20 à $-61 \%$ ) significative de la lipolyse, dans 2 cas sur 5 pour le tissu adipeux périrénal et dans 2 cas sur 3 pour le tissu adipeux sous-cutané, où la lipolyse stimulée est plus élevée. Sur les 
TABL. 1. - Lipolyse du tissu adipeux bovin in vitro, basale ou en présence de differents effecteurs.

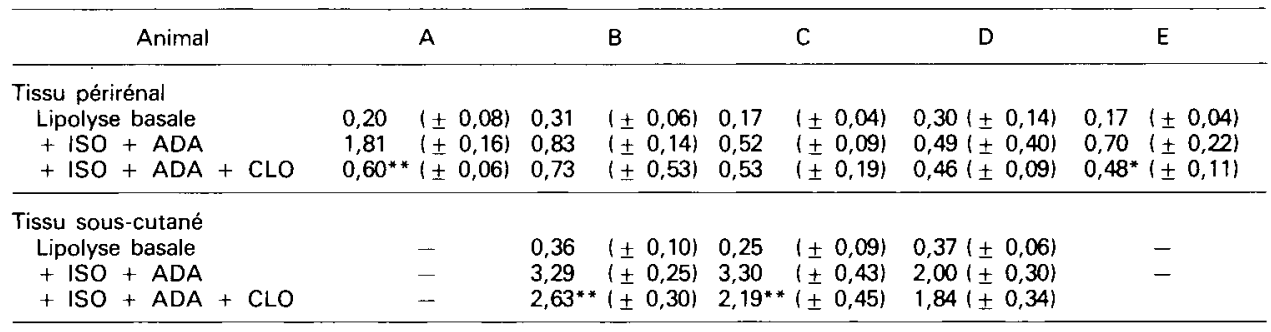

La lipolyse (moyenne \pm écart-type, $n=4$ ) est exprimée en micromoles de glycérol libéré $/ \mathrm{h} / \mathrm{g}$ de matière sèche tissulaire. ISO = isoprénaline $0,04 \mathrm{mM} ; A D A=$ adénosine désaminase $0,5 \mathrm{u} / \mathrm{ml} ; C L O=$ clonidine $10^{-8} \mathrm{M} . \mathrm{A}, \mathrm{B}, \mathrm{C}=$ bœufs charolais, âgés d'environ 30 mois, de 650 à $790 \mathrm{~kg}$ de poids vif, normalement alimentés; $D=$ vache Pie-Noire en fin de lactation, âgée de 10 ans, pesant $720 \mathrm{~kg}$ et normalement alimentée ; $E=$ vache Pie-Noire en $4^{e}$ semaine de lactation, âgée de 3 ans, pesant $540 \mathrm{~kg}$ et à jeun depuis 3 jours. ${ }^{* *},{ }^{*}$ : Valeur significativement différente de la valeur "ISO + ADA ", P $<0,014$ ou $P<0,057$, test $U$ de Mann et Whitney.

5 bovins étudiés, 4 ont présenté une réponse à la clonidine dans au moins un des deux sites anatomiques considérés.

L'étude des courbes " dose-réponse » (fig. 1) montre que l'effet antilipolytique est, dans 3 cas sur 4 , plus marqué à faible qu'à forte concentration en clonidine. II est possible que cet effet soit masqué à forte concentration par un effet lipolytique de la clonidine par l'intermédiaire d'autres récepteurs, de type $\mathrm{H} 2$, pour lesquels elle aurait moins d'affinité (M. Lafontan, Communication personnelle), ce qui devra être confirmé par d'autres investigations.

En conclusion, cette étude a permis de mettre en évidence dans les tissus adipeux de bovin, en particulier sous-cutanés, un effet antilipolytique de la clonidine à faible concentration $\left(10^{-8}\right.$ à $\left.10^{-10} \mathrm{M}\right)$ suggérant l'existence de récepteurs de type alpha-2 chez cette espèce. Ceci devra être confirmé sur un plus grand nombre d'animaux, et par une étude des récepteurs membranaires à l'aide de radioligands spécifiques. La signification physiologique d'éventuelles variations du rapport entre les récepteurs bêta et alpha - 2 au cours des cycles d'engraissement et de lipomobilisation des bovins, en particulier pendant la lactation, reste à établir.

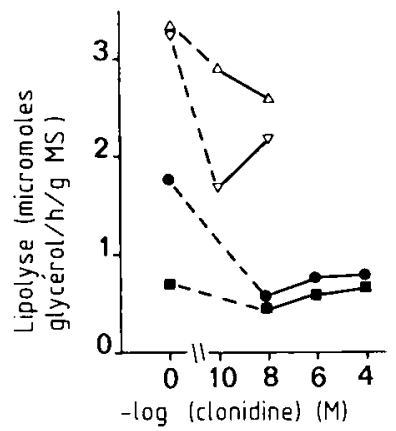

FIG. 1. Lipolyse du tissu adipeux bovin en présence d'isoprénaline et d'adénosine désaminase, et de différentes concentrations de clonidine. Symboles ouverts : sous-cutané ; fermés : périrénal. $, \Gamma, \bullet=$ animaux B, C, A, E (cf. tabl. 1). Quatre répétitions par point. 